\title{
ANÁLISE DE CONTEÚDO UTILIZANDO O WEBQDA: OPÇÃO METODOLÓGICA PARA CARACTERIZAR UMA CRIANÇA COM PARALISIA CEREBRAL
}

\author{
Davys Moreno', António Moreira ${ }^{1}$, Oksana Tymoshchuk ${ }^{1}$ e Carlos Marques² \\ 1Universidade de Aveiro, Portugal. davys.moreno@ua.pt, moreira@ua.pt, oksana@ua.pt \\ ${ }^{2}$ Escola Artística do Conservatório de Música Calouste Gulbenkian, Aveiro, Portugal. \\ carlospmarques@gmail.com
}

\begin{abstract}
Resumo. Com a finalidade de contribuir para a Educação Inclusiva das crianças com Necessidades Especiais no Ensino Artístico Especializado da Música em Portugal, iniciou-se no ano de 2018 um projeto de Investigação-Ação. O nosso objetivo é mostrar os resultados do diagnóstico realizado sobre a caracterização da criança com Paralisia Cerebral que originou o estudo. Para isso, foram realizadas nove entrevistas, considerando a encarregada de educação e os diferentes profissionais de educação e de saúde que trabalham com ela. Toda a informação compilada foi organizada e estudada mediante análise de conteúdo suportada por software na plataforma webQDA, recorrendo às ferramentas Fontes, Codificação e Questionamento, o que se revelou ser eficaz para a sua caracterização. Os resultados obtidos permitem observar que os entrevistados consideram relevante as características pessoais da criança numa perspetiva temporal. Ou seja, referem aspetos que remetem para o seu passado, presente e suas perspetivas futuras. Em todos estes aspetos evidencia-se a importância dada à utilização de Produtos de Apoio, às adaptações curriculares e à rede de apoio (pessoas) para que a criança em estudo tenha sucesso, nomeadamente na Aprendizagem da Música. Evidencia-se a necessidade de potenciar os diferentes fatores existentes nos contextos (meio envolvente), promovendo as acessibilidades.
\end{abstract}

Palavras-chave: Análise de Conteúdo; webQDA; Paralisia Cerebral; Inclusão; Ensino Artístico Especializado da Música.

\section{CONTENT ANALYSIS USING WEBQDA: METHODOLOGICAL OPTION TO CHARACTERIZE A CHILD WITH CEREBRAL PALSY}

\begin{abstract}
In order to contribute to the Inclusive Education of children with Special Needs in the Specialized Artistic Teaching of Music in Portugal, an Action-Research project started in 2018. Our objective is to show the results of the diagnosis made on the characterization of the child with Cerebral Palsy that originated the study. For this, nine interviews were carried out, considering the person in charge of the child's education and the different education and health professionals who work with that child. All the compiled information was organized and studied through content analysis supported by software on the webQDA platform, using the Sources, Coding and Questioning tools, which proved to be effective for the characterization of the child. The results obtained allow us to observe that the interviewees consider the child's personal characteristics relevant from a temporal perspective. That is, they refer to aspects that pertain to the child's past, present and future perspectives. In all of these aspects, the importance given to the use of Support Products, curriculum adaptations and the support network (people) is evident for the child under study to be successful, namely in the learning of Music. The need to enhance the different factors in the contexts (environment) is highlighted, promoting accessibility.
\end{abstract}

Keywords: Content Analysis; webQDA; Cerebral Palsy; Inclusion; Specialized Artistic Teaching of Music. 


\section{INTRODUÇÃO}

Em Portugal, o Decreto Lei (DL) No $344 / 1990$ de 2 de novembro estabelece que os cursos do Ensino Artístico Especializado (EAE) têm como objetivo desenvolver as aptidões dos alunos com vocação artística nos domínios das artes visuais, da dança e/ou da música, com a finalidade de futuramente poderem exercer uma profissão numa área artística. Neste contexto, e apesar da inclusão educativa ser considerada fundamental, tal como está preconizada pela Lei de Bases do Sistema Educativo do ano de 1986 e pelos DL. No 344/1990 de 2 de novembro, DL. No 03/2008 de 6 de janeiro e DL. No 54/2018 de dia 6 de julho, os cursos de Música das Escolas Artísticas ainda não estão preparados para acolher as crianças com Deficiência Motora decorrentes de Paralisia Cerebral (PC).

Considerando esta situação e tendo como finalidade contribuir para a mudança desta realidade, no ano de 2018 iniciou-se um projeto de Investigação-Ação com o intuito de procurar soluções para potenciar a inclusão de crianças com PC no EAE, transformando os atores e alterando as práticas de sala de aula. Inicialmente a investigação foi espoletada pela inscrição de uma criança com Paralisia Cerebral no Primeiro Ciclo de Ensino Básico ( ${ }^{\circ}$ CEB) do regime Supletivo, numa Escola Portuguesa do Ensino Artístico Especializado na área da Música. O presente artigo nasce da necessidade de conhecer a criança em estudo, identificando quais as suas reais capacidades e fragilidades. Utilizou-se a técnica de entrevista baseada nos conceitos teóricos da radiografia social de Urie Bronfenbrenner (Axelsson et al., 2019; Bronfenbrenner \& Evans, 2000; Martins \& Szymanski, 2004). Resumidamente, procurámos definir as caraterísticas pessoais da criança, a sua forma de aprendizagem e as suas dificuldades e capacidades e o que é necessário para potenciar o desenvolvimento das suas aprendizagens, nomeadamente da música.

\subsection{A criança e a Paralisia Cerebral}

A criança que motivou o estudo apresenta uma Paralisia Cerebral Diplégica com forma Discinética Grave nos membros superiores, o que implica a ocorrência de movimentos involuntários nessas extremidades. Possui também limitações bilaterais com alguma hipotonia, sendo os membros inferiores os mais afetados, apresentando também Epilepsia.

A Paralisia Cerebral (PC) é uma das perturbações do movimento mais comuns em crianças, afetando cerca de 2,1 em cada 1000 nados-vivos (Virella et al., \& Calado, 2018). Constituise como um conjunto de desordens permanentes que afetam o movimento e a postura, 
causando limitação nas atividades das crianças com esta condição (Elvrum et al., \& Vik, 2014; Magalhães et al., \& Batalha, 2011). As crianças com PC podem, também, apresentar outras limitações, tais como alterações sensoriais, cognitivas, de comunicação, comportamentais e epilepsia. $\mathrm{Na}$ atualidade existem muitos estudos sobre a Paralisia Cerebral que, dependendo dos problemas específicos que a criança possa ter, classificam a PC em diferentes subtipos (Bøttcher et al., \& Ödman, 2016), designadamente: (i) Paralisia Cerebral Discinética (Atetóide) ou Extrapiramidal: caracterizada por movimentos involuntários anormais, alterações de tónus muscular e transtornos de equilíbrio postural; (ii) Paralisia Cerebral Atáxica ou Cerebelosa: caracterizada por má coordenação motora (diminuição do tónus muscular manifestando-se através da ausência de coordenação e desequilíbrio); e (iii) Paralisia Cerebral Espástica ou Piramidal: uma condição de rigidez muscular (aumento do tónus muscular).

Além destas classificações, dependendo da parte do corpo afetada, a condição das Crianças com PC pode ter outras caracterizações (Bøttcher et al., \& Ödman, 2016; Elvrum et al., \& Vik, 2014; Magalhães et al., \& Batalha, 2011): (i) Paralisia Cerebral Hemiplégica ou Hemiparesia: também chamada de Paralisia Cerebral Unilateral, na qual metade do corpo é afetado, mas o maior comprometimento é nos membros superiores; (ii) Paralisia Cerebral Diplégica: também chamada de Paralisia Cerebral Bilateral, nesta condição o predomínio do comprometimento motor é nos membros inferiores, mas também pode haver algum comprometimento dos membros superiores; (iii) Paralisia Cerebral Tetraplégica: também chamada de Paralisia Cerebral Quadriplégica, nesta condição os membros superiores, os membros inferiores e o tronco podem estar comprometidos.

Lamentavelmente, na nossa pesquisa bibliográfica não encontrámos estudos relevantes sobre a inclusão de crianças com esta condição de Paralisia Cerebral no Ensino da Música Especializada. Assim, fomos procurar autores que nos ajudassem a analisar os aspetos do desenvolvimento da criança, do contexto em que vive e das suas interações. A teoria Ecológica de Urie Bronfenbrenner apresentou-nos essa possibilidade.

\subsection{Teoria da Ecologia e do Desenvolvimento Humano de Bronfenbrenner}

Bronfenbrenner explica que o desenvolvimento humano é uma progressiva acomodação entre o ser humano ativo e o seu entorno imediato, o que inclui dimensões conceptuais como pessoa, processo, contexto e tempo (Axelsson et al., 2019; Bronfenbrenner \& Evans, 
2000). Além disso, o processo de aprendizagem está influenciado pelas relações que se estabelecem entre: (i) os diferentes ambientes (meio envolvente), (ii) entre estes ambientes e os contextos, e (iii) entre os ambientes e os contextos de maior alcance, os quais chegam também a estar inclusos noutros ambientes e noutros contextos (Axelsson et al., 2019; Bronfenbrenner \& Evans, 2000; Martins \& Szymanski, 2004). É através destas premissas que Bronfenbrenner estabelece a ideia de um "ambiente ecológico." Este ambiente deve ser entendido como um conjunto de estruturas seriadas, em que cada estrutura se estabelece por dentro da outra (Axelsson et al., 2019; Martins \& Szymanski, 2004). Segundo esta ótica, poder-se-á potenciar o desenvolvimento da criança em estudo através duma intervenção, que deverá considerar os diferentes fatores que existem em diversos contextos e que se relacionam entre os seus diferentes meios envolventes (Figura 1). Estes meios envolventes situam-se mais ou menos próximos entre si e, devido a isso, como detalharemos a seguir, podem exercer influências diretas ou indiretas na criança em estudo (Axelsson et al., 2019; Bronfenbrenner \& Evans, 2000; Martins \& Szymanski, 2004):

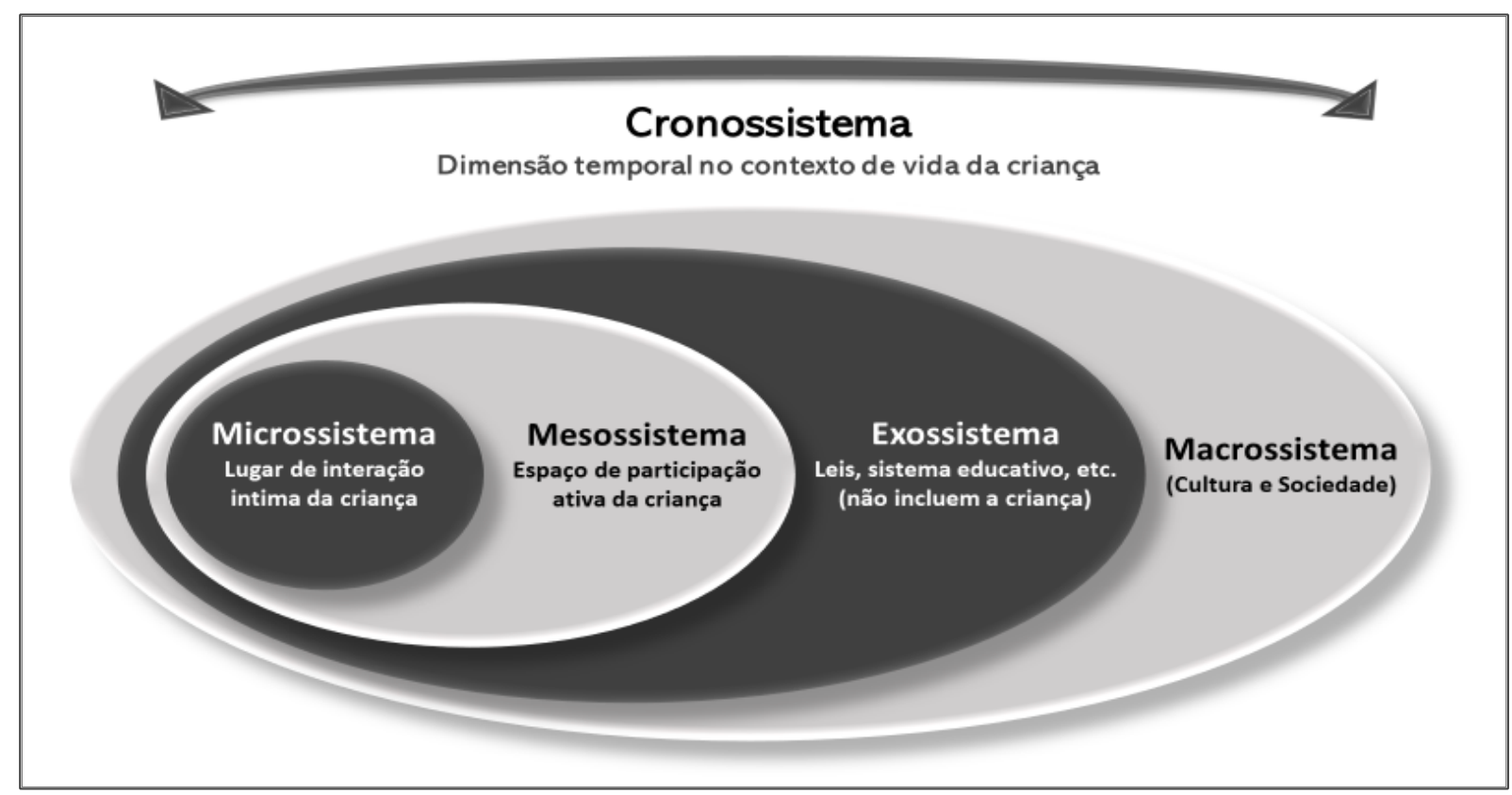

Figura 1. Modelo ecológico do desenvolvimento humano de Urie Bronfenbrenner

- Microssistema é formado pelos grupos que têm contacto direto com a criança em estudo, por exemplo a família, a escola, as terapias, e pelas caraterísticas físicas, psicológicas e sociais que são próprias da criança. Existe neste sistema uma relação que ocorre em ambas as direções, ou seja, é evidente a importância que estes grupos têm no desenvolvimento da criança, mas a criança também é capaz de modificar as perspetivas destes grupos em relação a si; 
- Mesossistema é formado pelas inter-relações que existem entre dois ou mais grupos do Microssistema nos quais a criança participa ativamente. Por exemplo, a relação dos pais da criança em estudo com os professores tem um impacto direto no desenvolvimento da criança;

- Exossistema consiste num ou mais ambientes que não incluem a criança como participante ativa, mas tem influência no seu desenvolvimento de forma indireta. Por exemplo, situação laborais dos pais, situação familiar dos professores, etc.;

- Macrossistema está situado num plano muito mais distante do desenvolvimento da criança, mas devido às interações sociais que podem chegar a afetá-la, acaba por ser um sistema crucial. Está ligado a caraterísticas da cultura e ao momento histórico-social em que a criança em estudo está imersa;

- Cronossistema tem a ver com a passagem do tempo e os acontecimentos que podem ter uma influência significativa. Refere-se ao momento atual da vida da criança em estudo.

Tendo a informação sobre a condição de Paralisia Cerebral e observando a importância de analisar os contextos em que a criança se desenvolve, passamos a delinear o nosso objetivo de investigação.

\subsection{Objetivo da Investigação}

O propósito deste estudo é a caracterização de uma criança com a condição de Paralisia Cerebral, que frequenta $01^{\circ}$ ano do Primeiro Ciclo de Educação Básica numa escola regular, através da aplicação de inquéritos por entrevista a família e profissionais de educação e saúde envolvidos nos processos educativos da criança. Para compilar, analisar e apresentar os resultados obtidos das nove entrevistas, utilizamos a ferramenta de análise de conteúdo webQDA.

Pretendemos conhecer quais são as competências da criança e as suas necessidades específicas para aprender, e poder frequentar uma Escola Artística Especializada da Música em regime supletivo. Para isso, fomos procurar informação no seu meio envolvente, entrevistando a encarregada de educação, os professores e os técnicos que trabalham com a criança, na escola e nas terapias. Tendo em conta a nossa finalidade, pensámos em perguntas que norteassem a nossa procura de informação (Quadro 1). Nesse sentido, especificámos os seguintes objetivos que fizemos corresponder às perguntas a colocar: 
Quadro 1. Objetivos e perguntas a colocar

\begin{tabular}{l|c} 
Objetivos & Perguntas \\
\hline $\begin{array}{c}\text { Saber como a criança é, quais são as suas caraterísticas pessoais, qual é a } \\
\text { representação dos profissionais ao interagir com a criança (como eles a vêm) }\end{array}$ & $\begin{array}{c}\text { Fale-nos um pouco sobre a sua } \\
\text { experiência ao interagir com a criança. } \\
\text { Como ela é? }\end{array}$ \\
\hline $\begin{array}{c}\text { Saber especificamente como a criança comunica e interage, conhecer a perceção } \\
\text { dos profissionais sobre a forma de comunicar e interagir da criança }\end{array}$ & $\begin{array}{c}\text { Como considera que a criança interage e } \\
\text { comunica com os outros? }\end{array}$ \\
\hline $\begin{array}{c}\text { Saber como é a aprendizagem da criança, o que os profissionais conhecem sobre } \\
\text { a forma como a criança aprende }\end{array}$ & $\begin{array}{c}\text { Como considera que a criança aprende? } \\
\text { Pode especificar? }\end{array}$ \\
\hline $\begin{array}{c}\text { Saber o que pode facilitar ou dificultar a Aprendizagem da criança. Qual é a } \\
\text { percepção que os profissionais têm sobre os facilitadores que a criança tem e quais } \\
\text { são as suas dificuldades para aprender }\end{array}$ & $\begin{array}{c}\text { Que facilidades e/ou dificuldades de } \\
\text { aprendizagem a criança tem? }\end{array}$ \\
$\begin{array}{c}\text { Saber o que pode facilitar ainda mais a aprendizagem da criança. O que os } \\
\text { profissionais pensam que poderá facilitar ainda mais a sua aprendizagem }\end{array}$ & $\begin{array}{c}\text { O que poderia facilitar mais a sua } \\
\text { aprendizagem? }\end{array}$ \\
\hline $\begin{array}{c}\text { Saber o que pode facilitar ainda mais a aprendizagem da criança na música. O } \\
\text { que os profissionais pensam que poderá facilitar ainda mais a sua aprendizagem } \\
\text { musical } \\
\text { Pergunta aberta para eventuais assuntos que os profissionais considerem } \\
\text { relevantes e que não foram abrangidos pelas questões anteriormente colocadas }\end{array}$ & $\begin{array}{c}\text { O que poderia facilitar mais a sua } \\
\text { aprendizagem especifica da música? }\end{array}$ \\
\hline
\end{tabular}

Partindo dos objetivos e das questões formuladas, passaremos a explicitar os procedimentos metodológicos considerados para o desenvolvimento da nossa investigação, nomeadamente o processo de aplicação e de análise dos dados.

\section{METODOLOGIA}

Considerando as perguntas enunciadas (Quadro 1), elaborámos um guião de entrevista que foi validado por profissionais especialistas das áreas da tecnologia, do ensino da música, da inclusão escolar e da saúde.

Com estes guiões, nos meses de novembro e dezembro de 2019, entrevistámos a encarregada de educação, quatro profissionais da educação e quatro profissionais da saúde que trabalham com a criança em estudo, nomeadamente: (i) na escola - a professora titular da turma, a professora de educação especial, a assistente operacional e o coordenador do estabelecimento de ensino; (ii) na Associação Portuguesa de Paralisia Cerebral (APPC) - a Terapeuta da Fala, a Terapeuta Ocupacional, a Técnica de Psicomotricidade e a Fisioterapeuta. Estes profissionais autorizaram a gravação em formato áudio e o tratamento das suas entrevistas através de consentimento informado. As entrevistas foram posteriormente transcritas em Word e a sua transcrição validada pelos respetivos entrevistados. Para a caracterização da criança, além destas entrevistas incluiu-se a informação dos relatórios clínicos da criança em estudo. 
Toda a informação compilada foi submetida a tratamento através da técnica de análise de conteúdo suportada pelo software webQDA ${ }^{1}$ (Costa \& Amado, 2018; Coutinho, 2018). Este software possibilitou a organização e sistematização da análise de dados, potenciando a definição das dimensões (Costa \& Amado, 2018) necessárias ao tipo de metodologia descritiva e qualitativa que utilizámos neste estudo. Mais especificamente, no sistema de Fontes internas no webQDA, foram inseridos os arquivos de texto referentes à transcrição de cada entrevista e a informação dos relatórios clínicos da criança. Começámos por realizar uma busca de palavras mais frequentes nas entrevistas e nos relatórios, eliminando as palavras com menos de 4 carateres, o que deu origem a uma nuvem de palavras. Estes resultados foram orientadores para iniciar a Codificação das fontes (entrevistas e relatórios clínicos).

Com esta base partimos para inferências, através da leitura dos dados, de forma indutiva. Foram realizadas leituras das respostas a cada questão, buscando padrões e comparando os dados. Como o guião de entrevistas foi constituído por perguntas abertas, a informação recolhida em cada pergunta não foi apenas direcionada para aquela pergunta em questão e sim considerada no global. Deste modo, a categorização foi feita por segmentos de texto de forma indutiva. Esta levou-nos a uma organização por temáticas de acordo com a informação compilada e não de acordo com a ordem das perguntas. Em seguida, foi feita uma análise das frequências das categorias relacionadas com cada temática. Os sujeitos de pesquisa foram indexados a "Classificações" para podermos relacioná-los com as categorias de análise na plataforma webQDA.

A partir da frequência das categorias, passamos ao "Questionamento", fazendo comparações entre os grupos de profissionais da educação e da saúde, utilizando a ferramenta "Matrizes" existente na plataforma webQDA. Para isso excluímos as categorias ligadas às respostas obtidas na entrevista da encarregada de educação e nos relatórios clínicos, utilizando o separador "Restrições" do menu "Matrizes". Estes resultados foram exportados para o Excel e transpostos em percentagens para análise.

Considerando o nosso objetivo de investigação - caracterização da criança - partimos em seguida para a apresentação dos dados obtidos e da sua análise.

\footnotetext{
${ }^{1}$ https://www.webqda.net/
} 


\section{ANÁLISE DOS RESULTADOS}

Num primeiro momento, observámos que os resultados obtidos na análise das categorias através das palavras mais frequentes nas entrevistas (figura 2), giravam em torno da criança em estudo. Estas fazem referência à utilização do computador, à sua aprendizagem, às suas dificuldades, ao fazer, à sua comunicação e à música. Por outro lado, a pesquisa de palavras mais frequentes nos relatórios clínicos (figura 3), aponta compreensivelmente para referências técnicas à condição de Paralisia Cerebral, aos Produtos de Apoio, ao nível, à criança, à instituição e, consequentemente, à reabilitação.

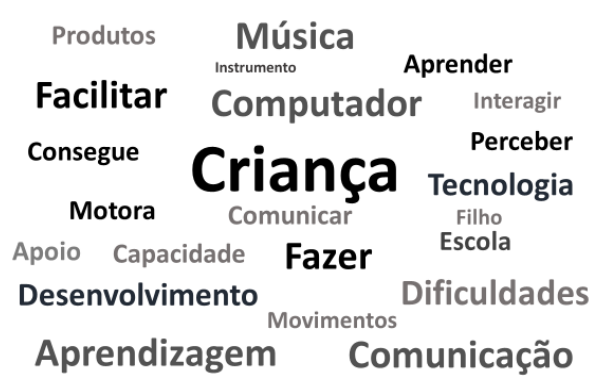

Figura 2. Palavras mais frequentes nas entrevistas.

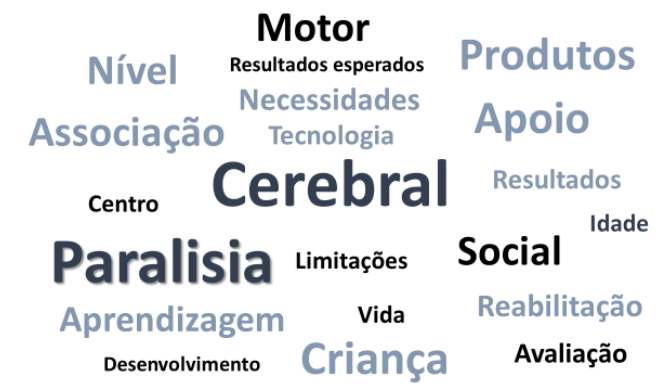

Figura 3. Palavras mais frequentes nos relatórios

Realizando o "output" dos resultados desta última nuvem de palavras no software webQDA, observamos que os conteúdos nos dizem que a criança tinha 7 anos (na data dos relatórios clínicos e psicológicos). Possui a condição de Paralisia Cerebral Diplégica, com forma Discinética Grave nos membros superiores, desloca-se com Cadeira de Rodas e Andarilho. Possui um desenvolvimento cognitivo consideravelmente acima da média. Não consegue falar nem escrever de forma "tradicional", mas interage com os seus pares e comunica tudo o que precisa através de gestos, expressões faciais e utilizando Produtos de Apoio: Computador portátil, software GRID $3^{2}$ e a ferramenta de acesso pelo olhar PC Eye Mini ${ }^{3}$.

Num segundo momento, a análise da totalidade das categorias formuladas fez perceber que tanto os profissionais da educação como da saúde, em relação à criança, referiam as

${ }^{2}$ GRID 3 é um software adequado a utilizadores com limitações Neuromotoras cognitivas ou da Fala. A sua utilização necessita de ser complementada com acessórios adaptados, neste caso com a utilização do PC Eye Mini.

${ }^{3}$ PC Eye Mini (Tobii Dynavox) é uma câmara que permite aos utilizadores com limitações Neuromotoras, o acesso ao computador através do olhar. Permite trabalhar com qualquer aplicação que possa ser controlada com o rato. 
mesmas características, cuja temática remetia para quatro grandes grupos de informação (Figura 4).

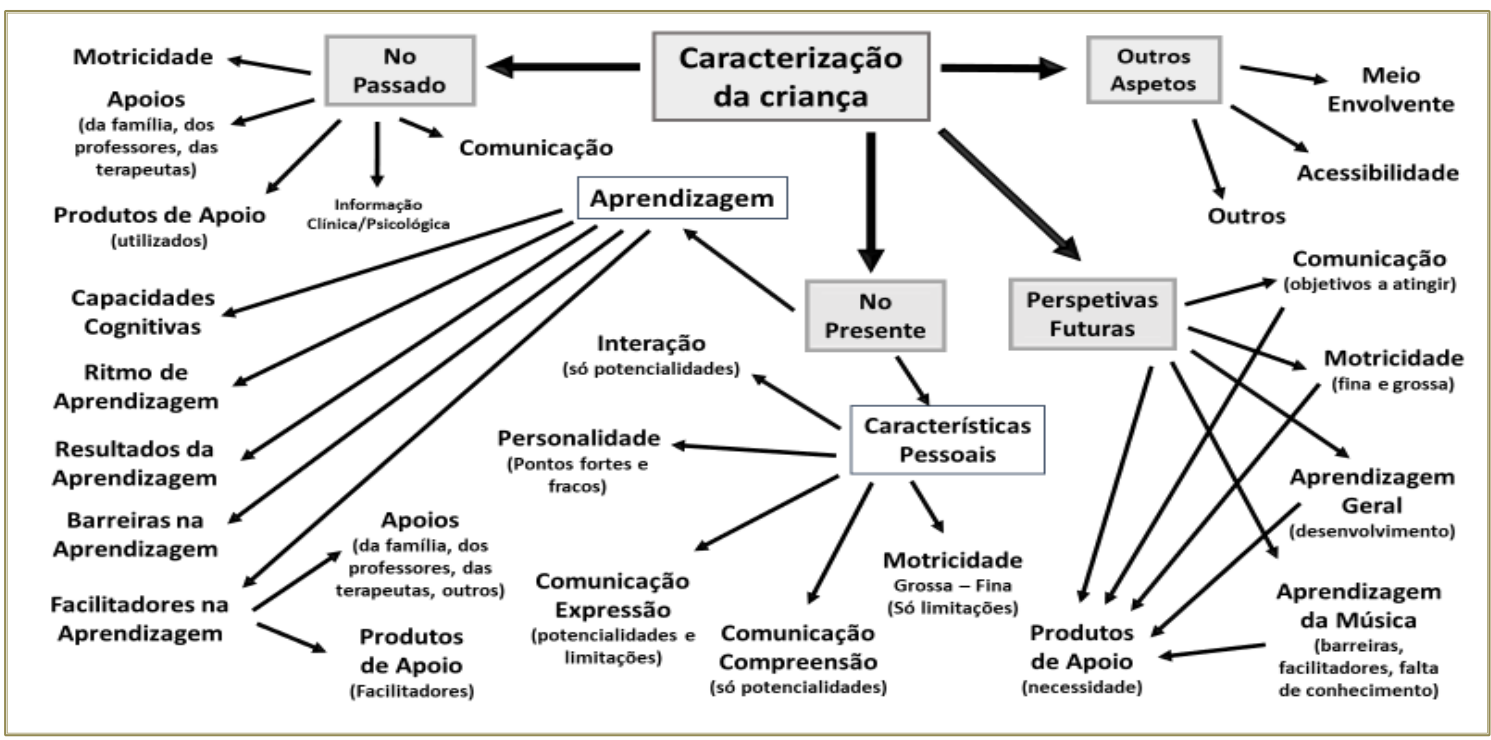

Figura 4. Categorias dos grandes grupos de informação

Estes grupos de informação estão relacionados com categorias que remetem para aspetos temporais, designadamente: (i) o passado da criança (inclui os relatórios clínicos); (ii) o presente da criança (como ela é, como aprende); (iii) o futuro da criança (perspetivas futuras); e (iv) outros (meio envolvente e acessibilidades).

\subsection{Presente da criança}

Neste grupo de informação incluem-se as respostas dos entrevistados ligadas às categorias relacionadas com: (i) as características pessoais da criança, como a criança é (Gráfico 1); (ii) a sua Aprendizagem, como a criança aprende no momento presente (Gráfico 2).

Entre as categorias com maior frequência relacionadas com as características pessoais da criança (Gráfico 1), encontram-se todas as que dizem respeito à "Comunicação" da criança (“Comunicação - Compreensão"; "Com. - Expressão Potencialidades" e "Com. - Expressão Limitações") e à sua "Interação", evidenciando-se os aspetos positivos da sua personalidade. Cabe destacar que nestas categorias os conteúdos remetem para o facto da criança ser vista como: "alegre, simpática, com boa capacidade cognitiva e muito comunicativa, com boa interação social, bastante interessada pelo meio envolvente, sempre bem-disposta, muito viva, muito esperta". 


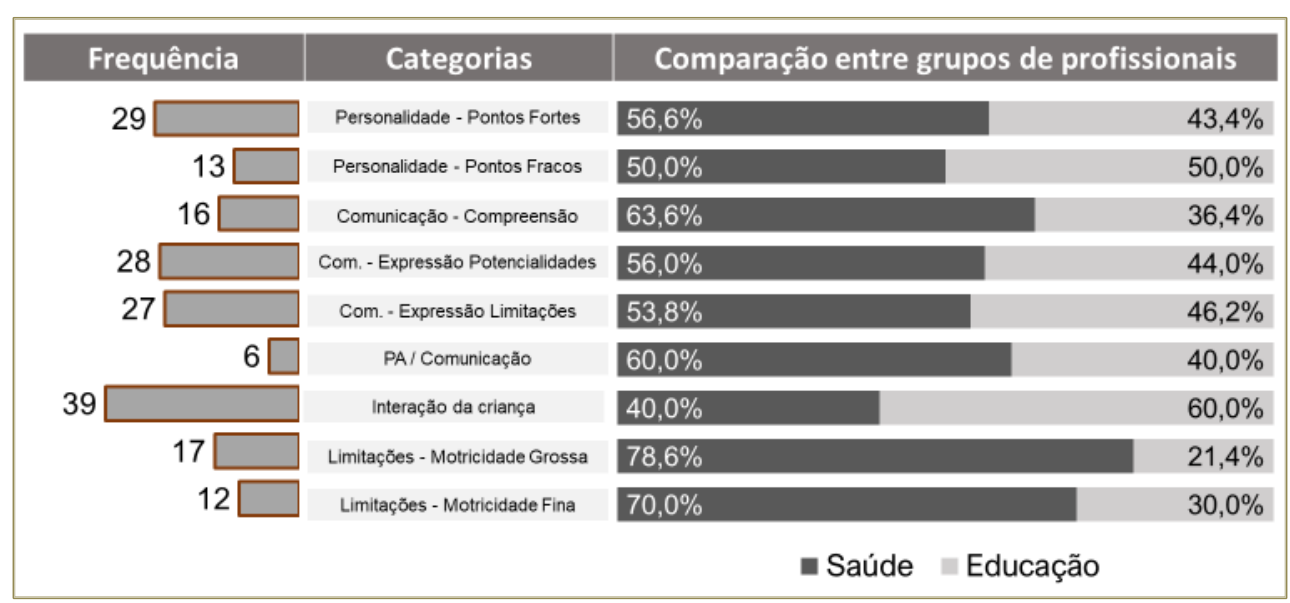

Gráfico 1. Frequência por Categorias e comparação entre grupos de profissionais - Características da Criança

Comparando as percentagens entre os profissionais da saúde e da educação (Gráfico 1), observamos que quase todos os resultados são idênticos entre os dois grupos de entrevistados. No entanto, nas categorias relacionadas com "Limitações - Motricidade Grossa", "Limitações - Motricidade Fina", "PA/Comunicação" e a "Comunicação Compreensão" o grupo de profissionais da saúde apresenta maior percentagem que o grupo dos profissionais da educação. Podemos supor que esta situação está relacionada, com o facto destas categorias estarem mais relacionadas com a sua área de intervenção. Ao invés, nas categorias relacionadas com a "Interação da Criança", o grupo dos profissionais da educação possui maior percentagem, relativamente ao grupo de profissionais da saúde. Passaremos a citar algumas das evidencias registadas em ambos os grupos: "tem dificuldades no andar; tem problemas de coordenação motora e lamentavelmente não consegue articular os músculos para gerar as palavras"; "o ponto fraco é sem dúvida a parte motora"; "Em termos de comunicação, tem o computador, sabe escrever no computador e essa é uma forma real para que a comunicação dele seja mais fina, mais detalhada"; "gosta até de ser "o mandão da chuva" pelo que termina sendo uma criança super bem-disposta"; "os colegas percebem muito bem o que ele quer dizer"; "existe uma excelente comunicação entre ele e os seus colegas".

No Gráfico 2, observamos que as categorias com maior frequência em relação à "Aprendizagem da Criança", os entrevistados fazem referência aos "Resultados da Aprendizagem", às "Capacidades Cognitivas", e aos "Facilitadores/Produtos de Apoio", necessários para que tenha acesso à aprendizagem, e ainda ao "Ritmo de Aprendizagem" da criança. 
Das respostas obtidas, destacamos: "é uma criança que aprende com facilidade, entende tudo, é como se tivesse um radar para captar as informações"; "a criança consegue aprender muito bem, aprende com rapidez"; "a nível de aprendizagem, é como outra criança qualquer a nível de suas capacidades cognitivas, só precisa de mais tempo para fazer as coisas, tem um ritmo próprio".

\begin{tabular}{|c|c|c|c|}
\hline Frequência & Categorias & \multicolumn{2}{|c|}{ Comparação entre grupos de profissionais } \\
\hline 25 & Capacidades Cognitivas & $60,0 \%$ & $40,0 \%$ \\
\hline 32 & Resultados da Aprendizagem & $40,0 \%$ & $60,0 \%$ \\
\hline 22 & Ritmo da Aprendizagem & $33,3 \%$ & $66,6 \%$ \\
\hline 14 & Barreiras na Aprendizagem & $87,5 \%$ & $12,5 \%$ \\
\hline 25 & Facilitadores / Produtos de Apoio & $21,0 \%$ & $79,0 \%$ \\
\hline 15[ & Facilitadores / Apoios (Pessoas) & $21,4 \%$ & $78,6 \%$ \\
\hline & & & \\
\hline
\end{tabular}

Gráfico 2. Frequência por Categorias e comparação entre grupos de profissionais - Aprendizagem da Criança

$\mathrm{Na}$ comparação das percentagens entre os grupos de profissionais (Gráfico 2), observamos uma grande diferença na categoria "Barreiras na Aprendizagem", na qual o grupo de profissionais da saúde dá maior relevância a esta categoria relativamente aos profissionais da educação. Contrariamente o grupo de profissionais da educação valoriza mais os "Facilitadores/Produtos de Apoio" e os "Facilitadores/Apoios (Pessoas)", ou seja, valorizam a utilização dos Produtos de Apoio e o apoio dos recursos humanos implicados na aprendizagem da criança, como por exemplo a Assistente Operacional que apoia a criança na escola.

O facto dos profissionais da educação valorizarem mais todas as categorias relacionadas com a "Aprendizagem" está em concordância com a sua área de intervenção. Contrariamente, a desvalorização das "Barreiras na Aprendizagem", poderá estar relacionado com os resultados na aprendizagem da criança que estes profissionais referem com maior percentagem, ou seja, como consideram que a criança tem sucesso nos "Resultados da Aprendizagem", provavelmente não valorizam as "Barreiras na Aprendizagem". 
Analisando as respostas dos profissionais da saúde, estes apontam como barreiras as questões ligadas à motricidade e às dificuldades na fala, por exemplo: "suas dificuldades são devidas às suas limitações a nível motor e da linguagem".

Por outro lado, tal como observamos no Gráfico 1, os profissionais da saúde são os que fazem maior referência aos aspetos ligados à comunicação e motricidade e consequentemente, provavelmente por esse motivo, evidenciam mais barreiras nestas áreas.

\subsection{Referências sobre o passado da criança}

Ao falar do passado da criança, os entrevistados evidenciaram aspetos relacionados com a história do seu desenvolvimento, os quais categorizámos no grupo referente ao passado da criança (Gráfico 3).

$\mathrm{Na}$ análise das frequências das categorias registadas neste grande grupo (Gráfico 3), observamos maior frequência na "Informação Clínica/Psicológica" dos relatórios de desenvolvimento da criança, seguida das categorias "Comunicação", "Motricidade" (desenvolvimento motor).

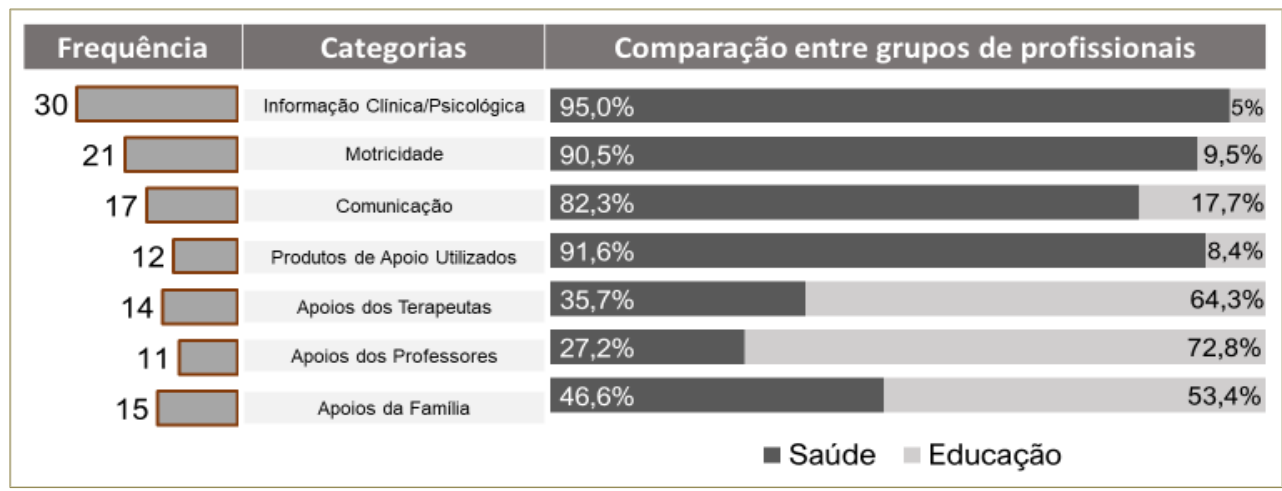

Gráfico 3. Frequência por Categorias e comparação entre grupos de profissionais - Referências sobre o passado

Comparando a informação dos grupos de profissionais (Gráfico 3), observamos que os profissionais da saúde fazem muito mais referências à "Informação Clínica/Psicológica", aos "Produtos de Apoio Utilizados", à "Motricidade" e à "Comunicação", todos ligados ao passado da criança. O grupo de profissionais da Educação dá maior relevância aos "Apoios" que a criança tem tido ao longo da sua história de vida, quer por parte da família, quer por parte dos terapeutas, quer por parte dos professores. Entre algumas evidencias destes aspetos podemos 
citar: "o seu desenvolvimento deve-se em parte aos estímulos que vai recebendo desde logo da mãe e da família"; "a Fisioterapia ajudou bastante no controle da cabeça e do tronco"; "tinha apoio de educadora de intervenção precoce uma vez por semana no domicílio".

A elevada frequência das respostas obtidas nas entrevistas dos profissionais da saúde, relativamente aos "Produtos de Apoio Utilizados" e à evolução da criança nas áreas da "Motricidade" e "Comunicação" está em concordância com as áreas de intervenção que estes profissionais possuem junto da criança desde tenra idade. Exemplos: "depois de passar por vários processos e tentativas de quadros de comunicação e de tentar no computador, de facto, concluímos que a melhor solução para a comunicação da criança seria potenciar a sua comunicação através do olhar no computador".

\subsection{Perspetivas Futuras}

Neste grande grupo, englobámos as categorias correspondentes às respostas dos entrevistados que evidenciaram possibilidades futuras da criança, das quais algumas dizem respeito à Aprendizagem da Música (gráfico 4).

As categorias que apresentam maior frequência (Gráfico 4), são as que estão relacionadas com as "Barreiras na Aprendizagem da Música", as que referem a utilização de "Produtos de Apoio para o Ensino da Música", seguidas da "Falta de Conhecimento (não sei)" e as "Adaptações Curriculares no Ensino da Música". Estas respostas podem estar relacionadas com a perspetiva da frequência de aulas de música no futuro, por parte da criança. Como evidencias da falta de conhecimento são exemplo as seguintes respostas: "não sei, realmente não imagino qual pode ser o instrumento que esta criança poderia tocar"; "a criança não tem acesso a atividades artístico-musicais".

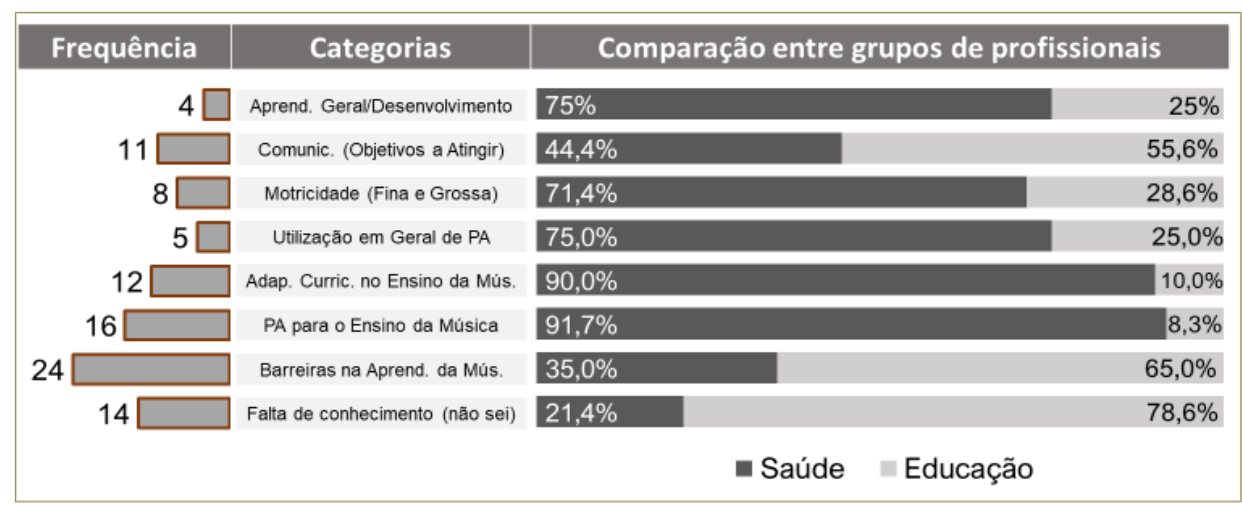

Gráfico 4. Frequência por Categorias e comparação entre grupos de profissionais - Perspetivas Futuras 
Comparando os dois grupos de Profissionais (Gráfico 4), observamos que a necessidade de "Produtos de Apoio para o Ensino da Música" e "Adaptações Curriculares no Ensino da Música", são mais referenciados pelo grupo de profissionais da saúde relativamente ao grupo de profissionais da educação. Estes últimos evidenciam maior "Falta de Conhecimento" e perspetivam maiores "Barreiras na Aprendizagem da Música". Algumas evidencias que observamos no grupo de profissionais da Educação são: "o que poderia facilitar a aprendizagem da música... será... não imagino o que poderia facilitar a sua aprendizagem musical"; "em verdade, não sei responder..."; "para a música, é uma dúvida, não consigo perceber como é que o ensino da música será feito"; "quando falamos do Ensino da Música, entramos num tema um bocadinho mais complicado"; "se passamos a prática de um instrumento, aquela falta de capacidade motora, não sei, realmente não sei o que se poderia fazer aí".

Entre as respostas dos profissionais da Saúde, parece existir uma perspetiva mais postiva relativamente a uma futura aprendizagem da música, por exemplo: "Na música, aprendizagem na música, eu acho que deveriam existir os instrumentos adaptados em vez de instrumentos clássicos para que os pudesse tocar"; "tenho a certeza que através do olhar vai conseguir aprender música, ao invés de ser de mão, pois ele não tem tanta destreza manual, mas através do olhar, um programa que pudesse ter vários instrumentos ou uns dois ou três, os que fossem, onde ele pudesse escolher um desses e através do programa dele que ele tem no computador, assim penso que poderia tocar".

\subsection{Outros aspetos}

Neste conjunto de categorias englobamos a informação relativa a aspetos não diretamente relacionados com a criança e sim com a questão das acessibilidades e o meio envolvente, tais como: "os espaços que frequenta deveriam ser todos acessíveis e adaptadas com os produtos de apoio necessários para que se sinta seguro e confortável"; "para ele, assim como para qualquer outra criança que tenha questões relacionadas com a mobilidade, a eliminação das barreiras arquitetónicas e a adaptação dos espaços é fundamental".

\section{CONCLUSÕES}

A utilização do software webQDA constituiu um excelente apoio metodológico enquanto ferramenta para suportar a técnica de análise de conteúdo. Para além de facilitar a 
categorização dos dados, permitiu questionar a possível relação entre os mesmos. Deste modo, o nosso grande objetivo de caracterização da criança foi plenamente conseguido.

A análise de conteúdo da informação compilada através de entrevistas, permitiu-nos observar que os profissionais estão bem conscientes das características da criança em estudo. Consideram que ela possui um bom desenvolvimento cognitivo, o que inclui as capacidades de comunicação e interação necessárias para poder desenvolver as suas aprendizagens, e possivelmente, as suas potencialidades artísticas na música. Além disso, os entrevistados consideram que se the proporcionamos o acesso a um "instrumento" através da utilização de Produtos de Apoio, algumas adaptações curriculares e uma boa rede de apoio (pessoas), a criança poderá frequentar também a Aprendizagem da Música.

Passamos a citar alguns exemplos das referências obtidas através das entrevistas: "no conservatório seria necessário o apoio diário de uma assistente operacional para a satisfação das necessidades básicas, mobilidade, correção e alternância de posicionamentos, bem como na concretização das atividades e tarefas"; "penso que é muito importante que sejam desenvolvidos programas, nomeadamente na música, que facilitem a sua aprendizagem musical, porque estas crianças já ficam excluídas do ensino da música"; "seria bom que nós pudéssemos ter, de alguma forma, algum instrumento, algum software ou algo para que a criança possa operar, possa controlar os ritmos e ser capaz de coordenar os movimentos"; "ele faz-nos acreditar que vai ter um futuro promissor na aprendizagem e porque não, na música?".

Concluindo, para que seja possível que a criança com PC em estudo possa aceder ao Ensino Especializado da Música, tal como salienta Urie Bronfenbrenner (Axelsson et al., 2019; Bronfenbrenner \& Evans, 2000; Martins \& Szymanski, 2004), precisamos fortalecer a estrutura dos relacionamentos que existem ao seu redor, possibilitando-lhe uma boa rede de apoio para potenciar o seu desenvolvimento, devem-se considerar os diferentes fatores que existem nos diversos contextos que envolvem a criança e que se relacionam entre si. Um ambiente que promova as acessibilidades no Ensino Artístico Especializado da Música. Mais especificamente, tornando o espaço da Escola Especializada acessível, realizando adaptações dos programas do Ensino Artístico Especializado da Música, e ainda, promovendo a utilização de "Produtos de Apoio" para a Aprendizagem da Música, poderemos supor que a criança em estudo poderá desenvolver as suas competências musicais. Como perspetivas futuras de estudo, estes resultados leva-nos a pensar que será 
importante investigar qual a experiência dos professores de música, no ensino de crianças com deficiência motora decorrente de Paralisia Cerebral, em diferentes contextos.

Agradecimentos. Este trabalho é financiado por Fundos Nacionais através da FCT - Fundação para a Ciência e a Tecnologia, I.P. no âmbito do projeto UIDB/00194/2020.

\section{REFERÊNCIAS}

Axelsson, A., Lundqvist, J., \& Sandberg, G. (2019). Influential factors on children's reading and writing development: The perspective of parents in a swedish context. Early Child Development and Care. Advance online publication. https://doi.org/10.1080/03004430.2019.1590348.

Bøttcher, L., Stadskleiv, K., Berntsen, T., Christensen, K., Korsfelt, Å., Kihlgren, M., \& Ödman, P. (2016). Systematic cognitive monitoring of children with cerebral palsy-the development of an assessment and follow-up protocol. Scandinavian Journal of Disability Research, 18(4), 304-315. https://doi.org/10.1080/15017419.2015.1091035.

Bronfenbrenner, U. (1979). Contexts of child rearing: Problems and prospects. American Psychologist, 34(10), 844-850. https://doi.org/10.1037/0003-066X.34.10.844.

Bronfenbrenner, U., \& Evans, G. W. (2000). Developmental science in the 21st century: Emerging questions, theoretical models, research designs and empirical findings. Social development, 9(1), 115-125.

Costa, A. P., \& Amado, J. (2018). Análise de conteúdo suportada por software. Aveiro (PRT): Ludomedia.

Coutinho, C. P. (2018). Metodologia de investigação em ciências sociais e humanas: Teoria e Prática. Coimbra: Almedina. ISBN 978-972-40-5137-6.

Elvrum, A. K., Andersen, G. L., Himmelmann, K., Beckung, E., Ohrvall, A. M., Lydersen, S., \& Vik, T. (2014). Bimanual fine motor function (BFMF) classification in children with cerebral palsy: aspects of construct and content validity. Physical \& Occupational Therapy in Pediatrics, 36(1), 1-16.

Lei de Bases do Sistema Educativo (1986). Lei n 46/86, Diário da República n. ${ }^{\circ}$ 237/1986 de 14 de outubro (Ia Série), 3067 - 3081.

Magalhães, S., Lopes, R., Simas, F., Reis, V., Vasconcelos, M., \& Batalha, I. (2011). Paralisia cerebral na Criança - caraterização clínica e funcional. Revista Da Sociedade Portuguesa de Medicina Física e Reabilitação, 20(2).

Martins, E., \& Szymanski, H. (2004). A abordagem ecológica de Urie Bronfenbrenner em estudos com famílias. Estudos e pesquisas em esicologia, 4(1). http://pepsic.bvsalud.org/scielo.php?script=sci_arttext\&pid=S1808-42812004000100006.

Virella, D., Folha, T., Andrada, M. G., Cadete, A., Gouveia, R., Gaia, T., ... Calado, E. (2018). Paralisia Cerebral em Portugal no século XXI - Indicadores Regionais Crianças Nascidas entre 2001 e 2010, Registos de 2006 a 2015 ( $1^{\text {a }}$ ed). Lisboa: Federação das Associações Portuguesas de Paralisia Cerebral 